Article

\title{
Surface Plasmon Resonance (SPR) for the Evaluation of Shear-Force-Dependent Bacterial Adhesion
}

\section{Oleksandr Zagorodko ${ }^{1}$, Julie Bouckaert ${ }^{2, *}$, Tetiana Dumych ${ }^{2}$, Rostyslav Bilyy ${ }^{3}$, Iban Larroulet ${ }^{4}$, Aritz Yanguas Serrano ${ }^{4}$, Dimitri Alvarez Dorta ${ }^{5}$, Sebastien G. Gouin ${ }^{5}$, Stefan-Ovidiu Dima ${ }^{1,6,7}$, Florin Oancea ${ }^{7}$, Rabah Boukherroub ${ }^{1}$, and Sabine Szunerits ${ }^{1, *}$}

1 Institute of Electronics, Microelectronics and Nanotechnology (IEMN),

UMR-CNRS 8520, Université Lille 1, Cité Scientifique, 59655 Villeneuve d'Ascq, France;

E-Mails: morjakzzz@gmail.com (O.Z.); phd.ovidiu.dima@gmail.com (S.-O.D.); rabah.boukherroub@univ-lille1.fr (R.B.)

2 Unité de Glycobiologie Structurale et Fonctionnelle (UGSF), UMR8576 du CNRS, Université Lille 1, 59655 Villeneuve d'Ascq, France; E-Mail: t.shkandina@gmail.com

3 Institute of Cell Biology, National Academy of Sciences of Ukraine, 79005 Lviv, Ukraine; E-Mail: r.bilyy@gmail.com

4 SENSIA SL, Poligono Aranguren, 9, Apdo. Correos 171, 20180 Oiartzun, Gipuzkoa, Spain; E-Mails: ilarroulet@ seimcc.com (I.L.); aritz_yanguas@ hotmail.com (A.Y.S.)

5 LUNAM Université, CEISAM, UMR 6230 du CNRS, 2, rue de la Houssinière, BP 92208, 44322 Nantes Cedex 3, France; E-Mails: dimitri.alvarez-dorta@univ-nantes.fr (D.A.D.); Sebastien.Gouin@univ-nantes.fr (S.G.G.)

6 Faculty of Applied Chemistry and Materials Science, University Politehnica of Bucharest, 1-7 Gheorghe Polizu, 011061 Bucharest, Romania

7 National R\&D Institute for Chemistry and Petrochemistry ICECHIM, 202 Splaiul Independentei, 060021 Bucharest, Romania; E-Mail: florino@ping.ro

* Authors to whom correspondence should be addressed;

E-Mails: julie.bouckaert@ univ-lille1.fr (J.B.); sabine.szunerits@iri.univ-lille1.fr (S.S.);

Tel.: +33-3-6253-1729 (J.B.); +33-3-6253-1725 (S.S.); Fax: +33-3-6253-1701 (J.B. \& S.S.).

Academic Editors: Nicole Jaffrezic-Renault and Carole Chaix

Received: 30 April 2015 / Accepted: 19 May 2015 / Published: 26 May 2015

Abstract: The colonization of Escherichia coli (E. coli) to host cell surfaces is known to be a glycan-specific process that can be modulated by shear stress. In this work we investigate whether flow rate changes in microchannels integrated on surface plasmon 
resonance (SPR) surfaces would allow for investigating such processes in an easy and high-throughput manner. We demonstrate that adhesion of uropathogenic E. coli UTI89 on heptyl $\alpha$-D-mannopyranoside-modified gold SPR substrates is minimal under almost static conditions (flow rates of $10 \mu \mathrm{L} \cdot \mathrm{min}^{-1}$ ), and reaches a maximum at flow rates of $30 \mu \mathrm{L} \cdot \mathrm{min}^{-1}(\approx 30 \mathrm{mPa})$. This concept is applicable to the investigation of any ligand-pathogen interactions, offering a robust, easy, and fast method for screening adhesion characteristics of pathogens to ligand-modified interfaces.

Keywords: surface plasmon resonance (SPR); shear force enhancement; flow rate; Escherichia coli (E. coli); carbohydrates

\section{Introduction}

Formation of biocomplexes (e.g., antigen-antibody, DNA-DNA, proteins-nucleic acids, etc.) is an affinity reaction present in most important biochemical processes involved in nature. This principle has found widespread use in designing bioanalytical assays. One of the widely used bioanalytical techniques for real-time monitoring of affinity interactions between immobilized biological components on a transducer surface and target molecules in solution is Surface Plasmon Resonance Spectroscopy (SPR) [1,2]. Over the years, SPR has shown its potential as an alternative to conventional biochemical methods for studying a wide range of bimolecular interactions with high sensitivity and selectivity [3-5]. SPR sensors have also been demonstrated to allow quantification of a wide range of pathogens through the detection of formed protein toxins [6-8], small molecule toxins [9,10], or the whole bacteria via surface-immobilized specific antibodies or bacteriophages [11-15]. Next to antibodies and bacteriophages, carbohydrate derivatives have been considered as possible SPR targets for bacterial toxins and pathogens [8,16,17]. Glycan-modified SPR interfaces were used by Bouckaert et al. for the determination of the affinity of FimH-carbohydrate interactions [18]. Szunerits and Bouckaert showed recently that the adhesion of uropathogenic and enterotoxigenic Escherichia coli (E. coli) clinical isolates, both of which express structurally characterized fimbrial adhesions, can be studied conveniently on glycan-modified SPR interfaces [17].

In this paper, we ask whether SPR, in addition to its confirmed quantitative character, has potential as an analysis tool for investigating the impact of shear on the adhesion of pathogens to surfaces and allows to extract information about the adhesion dynamics of pathogens. Bacterial cells are often dispersed in a flowing carrier fluid (e.g., water, urine, or blood); thus studying the dynamics of bacterial adhesion under controlled conditions of both flow and chemical environment is particularly relevant.

The impact of shear caused by the flow of fluids on bacterial adhesion to biotic and abiotic surfaces has indeed been considered in the past [19-22]. Thomas and co-workers observed that the adhesion of E. coli to mannose-coated surfaces was enhanced by shear stress and attributed this phenomenon to the formation of force-enhanced allosteric catch-bonds between the type- 1 fimbrial adhesion and surface-attached mannose moieties [20,22,23]. Experimental evidence for the shear-force-dependent adhesion was provided from data using molecular force spectroscopy with purified FimH and demonstrated that a tensile force extends the lifetime of the bond established between FimH and the 
mannose receptor [24]. More recently, Klinth et al. showed that the adhesive properties of pilated E. coli and specifically their dependence on $\mathrm{pH}$ can be investigated by force measurements with optical tweezers and SPR using purified P pili as well as whole bacteria [25].

In this paper, the dynamics of adhesion of E. coli onto heptyl $\alpha$-D-mannopyranoside (HM)-modified gold SPR interfaces is investigated. We focus on the effect of shear force on the initial adhesion of E. coli UTI89 mediated by FimH, a mannose-recognizing adhesin found at the tip of the type 1 pilus [26,27]. The data indicate that the presence of HM has a strong bearing on the measured adhesive capacity of E. coli UTI89. To examine the specificity of the bacterial adhesion for the sugar-modified plasmonic interfaces, we also interacted a type-1 fimbriated E. coli strain, UTI89 Q113K, carrying a mutation in FimH (glutamine 133 to lysine) and rendering it dysfunctional for mannose-binding, as well as UTI89 $\Delta$ fimH, with a deletion of the fimH gene from the fim operon, which therefore is hampered in the initiation of type-1 fimbrial biogenesis [17,28,41].

\section{Experimental Section}

\subsection{Materials}

11-mercaptoundecanoic acid (MUA), $N$-hydroxysuccinimide (NHS), $N, N^{\prime}$-dicyclohexylcarbodiimide (DCC), dimethyl formamide (DMF) and ethanol were purchased from Aldrich and used as received. Aminoheptyl $\alpha$-D-mannopyranoside (HM) was synthesized as reported previously [29].

\subsection{Formation of Glycans-Modified SPR Interfaces}

Gold-based SPR interfaces were provided by Sensia and used as received. Carboxylic acid-terminated self-assembled monolayers were formed through immersion of the gold substrate in an ethanolic solution of 11-mercaptoundecanoic acid $(1 \mathrm{mM})$ for $24 \mathrm{~h}$. The samples were rinsed with ethanol (three times) and water (three times) and dried under argon.

The carboxylic acid-terminated surface $(\mathrm{Au}-\mathrm{COOH})$ was immersed in DMF solution $(20 \mathrm{~mL})$ of DCC $(2 \mathrm{mM})$ and NHS $(2 \mathrm{mM})$ for $40 \mathrm{~min}$ to activate the COOH groups. The modified interfaces were further reacted overnight in a solution of aminoheptyl $\alpha$-D-mannopyranoside $(2 \mathrm{mM})$ in DMF under stirring to form the amide linkage. The interface was rinsed twice with DMF and then ethanol and thereafter dried under a gentle stream of nitrogen.

\subsection{Determination of the Amount of Glycans on the SPR Interfaces}

The amount of glycan on gold was determined by treatment with a phenol/ $\mathrm{H}_{2} \mathrm{SO}_{4}$ solution as described previously [30]. First, a calibration curve for aminoheptyl $\alpha$-D-mannopyranoside in solution was established using a phenolic aqueous solution (5 wt \%, $60 \mu \mathrm{L})$, concentrated $\mathrm{H}_{2} \mathrm{SO}_{4}(900 \mu \mathrm{L})$ which was added to an aqueous glycan solution $(60 \mu \mathrm{L})$, stirred for $10 \mathrm{~min}$, and then an absorption spectrum was recorded against blank sample without glycan. The absorbance of the solution was measured at two wavelengths, $\lambda_{1}=485$ and $\lambda_{2}=570 \mathrm{~nm}$, and the absorbance difference (A485-A570) was plotted as a function of the concentration of the glycan. The glycan-modified SPR interface was treated with phenol $/ \mathrm{H}_{2} \mathrm{SO}_{4}$ following the same protocol described above. 


\subsection{Instrumentation}

\subsubsection{SPR}

SPR measurements were performed with a commercial available SPR instrument called "Indicator" (provided by SENSIA, Oiartzun, Spain), working at a wavelength of $650 \mathrm{~nm}$. The instrument is equipped with a two-channel flow cell system that can be in a first approach modeled as a $12 \mathrm{~mm}$ long cell with an inner diameter of $0.5 \mathrm{~mm}$. The flow speed can be adjusted from 4 to $100 \mu \mathrm{L} \cdot \mathrm{min}^{-1}$. Each of the loops has a volume of $60 \mu \mathrm{L}$. The prisms used have a refractive index of $n=1.569$ (HBAK1, Schott Global) and have been modified by a Ti adhesion layer of $2 \pm 0.5 \mathrm{~nm}$ and a gold thin film of $47 \pm 2 \mathrm{~nm}$, both deposited by sputtering under vacuum.

\subsubsection{UV/Vis Measurements}

Absorption spectra were recorded using a spectrophotometer (Perkin Elmer Lambda UV/Vis 950) in plastic cuvettes with an optical path of $10 \mathrm{~mm}$. The wavelength range was 400-800 nm.

\subsubsection{X-Ray Photoelectron Spectroscopy}

X-ray photoelectron spectroscopy (XPS) experiments were performed in a PHl 5000 VersaProbeScanning ESCA Microprobe (ULVAC-PHI) instrument at a base pressure below $5 \times 10^{-9}$ mbar. Monochromatic $\mathrm{AlK}_{\alpha}$ radiation was used and the X-ray beam, focused to a diameter of $100 \mu \mathrm{m}$, was scanned on a $250 \mu \mathrm{m} \times 250 \mu \mathrm{m}$ surface, at an operating power of $25 \mathrm{~W}(15 \mathrm{kV})$. Photoelectron survey spectra were acquired using a hemispherical analyzer at pass energy of $117.4 \mathrm{eV}$ with a $0.4 \mathrm{eV}$ energy step. Core-level spectra were acquired at pass energy of $23.5 \mathrm{eV}$ with a $0.1 \mathrm{eV}$ energy step. All spectra were acquired at $90^{\circ}$ between X-ray source and analyzer and with the use of low-energy electrons and low-energy argon ions for charge neutralization. After subtraction of the Shirley-type background, the core-level spectra were decomposed into their components with mixed Gaussian-Lorentzian (30:70) shape lines using the CasaXPS software. Quantification calculations were performed using sensitivity factors supplied by PHI.

\subsection{Bacteria}

The wild-type UTI89 E. coli strain carries a few hundreds of mannose-sensitive type-1 fimbrial adhesins FimH. A strain called UTI89 Q133K had been made dysfunctional for mannose binding through a glutamine 133 to lysine mutation [17,28]. UTI89 $\Delta$ fimH bacteria carry no fimbriae. Upon plating on LB-agar complemented with the appropriate antibiotics, the bacteria were inoculated in LB plus antibiotics for $48 \mathrm{~h}$ static growth at $37{ }^{\circ} \mathrm{C}$, to optimize fimbrial expression. The bacterial pellet was obtained upon centrifugation, washed three times in phosphate-buffered saline (PBS), and then solubilized to an optical density at $600 \mathrm{~nm}\left(\mathrm{OD}_{600 \mathrm{~nm}}\right)$ of about 10 (agreeing with about $1 \times 10^{10}$ colony forming units $/ \mathrm{mL}$ ) for spectrometric determination of the optical densities. The bacteria were further diluted to $1 \times 10^{8} \mathrm{cfu} / \mathrm{mL}$ using PBS for SPR studies. 


\section{Results and Discussion}

\subsection{Modification of Gold SPR Interfaces with Aminoheptyl $\alpha$-D-Mannopyranoside (HM)}

The interaction of $E$. coli UTI89 with host tissue is known to be mediated by the $30 \mathrm{kDa}$ mannose-specific FimH protein, which is located on the tip of type 1 fimbriae [31]. Previous results demonstrated that the low micromolar affinity of E coli UTI89 to simple mannose can be overcome by using synthetic monovalent mannosides bearing hydrophobic [32] or simple alkyl [26] aglycons in the anomeric position. Aminoheptyl $\alpha$-D-mannopyranoside (HM) was in this respect identified as a particular promising ligand [29] and used in this work for the modification of SPR interfaces.

The covalent linking of HM to gold-based SPR interfaces was achieved in a two-step procedure (Figure 1a). First, an acid-terminated self-assembled monolayer (Au-COOH) was formed through immersion of the gold interface in an ethanolic solution of 11-mercaptoundecanoic acid (MUA) for $24 \mathrm{~h}$. Figure $1 \mathrm{~B}$ shows the $\mathrm{C} 1 \mathrm{~s}$ core level photoemission spectrum for the resulting $\mathrm{Au}-\mathrm{COOH}$ interface. The presence of the aliphatic carbon atoms results in a peak at $285.0 \mathrm{eV}$, while the feature at $289.1 \mathrm{eV}$ is due to the terminal carboxylic groups.

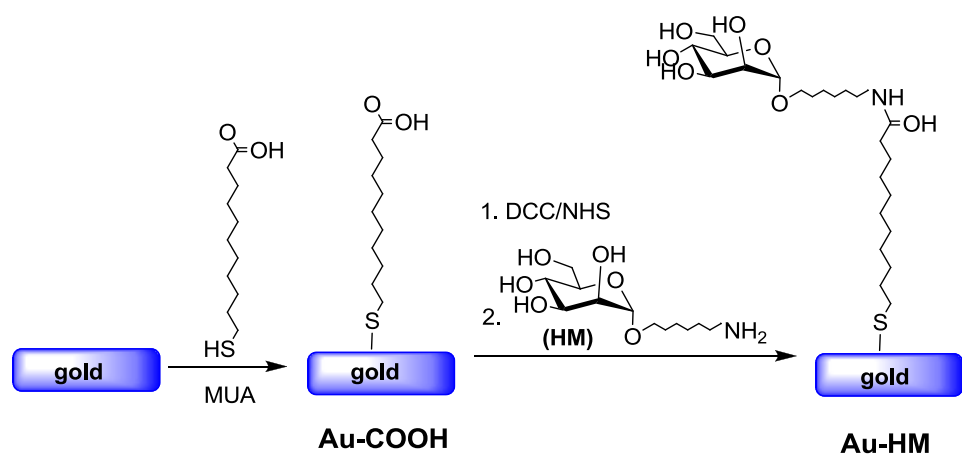

(a)

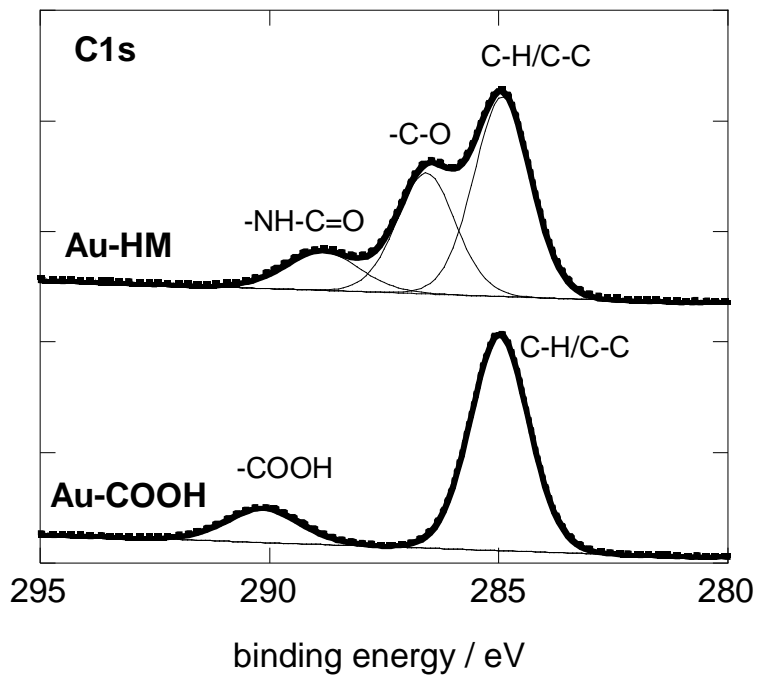

(b)

Figure 1. (a) Reaction scheme for the formation of aminoheptyl $\alpha$-D-mannopyranoside modified SPR interfaces; (b) C1s core level XPS spectra of Au-COOH and Au-HM interfaces. 
Aminoheptyl $\alpha$-D-mannopyranoside was successfully coupled to the $\mathrm{Au}-\mathrm{COOH}$ interface using peptide linkage chemistry between the terminal $-\mathrm{NH}_{2}$ groups of $\mathrm{HM}$ and $\mathrm{NHS}$-activated ester groups of the $\mathrm{Au}-\mathrm{COOH}$ interface (Figure 1a). The $\mathrm{C} 1 \mathrm{~s}$ core level spectrum of the Au-HM interface shows next to the peak at $285.0 \mathrm{eV}$ (aliphatic carbon atoms) contributions at $286.2 \mathrm{eV}$ and $288.1 \mathrm{eV}$, characteristic of $\mathrm{C}-\mathrm{O}$ bands of the integrated glycans and the formed amide bond, respectively (Figure 1b). The degree of sugar loading was determined using the classical phenol-sulfuric acid method as described in several papers by us [30,33]. A loading of $(8.5 \pm 0.6) \times 10^{14}$ molecules $\cdot \mathrm{cm}^{-2}$ was thus determined, in accordance with other reports on mannose-modified SPR surfaces [33,34].

\subsection{Adhesion Behavior of E. coli UTI89 to Au-HM under Different Flow Rates}

The interaction between E. coli $\left(10^{8} \mathrm{cfu} / \mathrm{mL}\right)$ and $\mathrm{Au}-\mathrm{HM}$ interfaces was investigated in real time using label-free interaction analysis in an SPR assay format (Figure 2). Figure 2a shows the change in the SPR signal over $30 \mathrm{~min}$ on $\mathrm{Au}$ and Au-HM interfaces upon interaction with E. coli UTI89. The binding ability of E. coli UTI89 to Au-HM was significantly larger than on gold alone, in line with the well-known glycans-mediated increase in pathogen adhesion. To underline the specific aminoheptyl $\alpha$-D-mannopyranoside-E. coli UTI89 interaction, the adhesion behavior of a strain called UTI89 Q133K, made dysfunctional for mannose binding through a glutamine 133 to lysine mutation [17,28], was investigated in addition. As seen in Figure 2b, UTI89 Q133K shows no sugar specific interaction and the change in the SPR signal recorded is the same for Au and Au-HM interfaces.

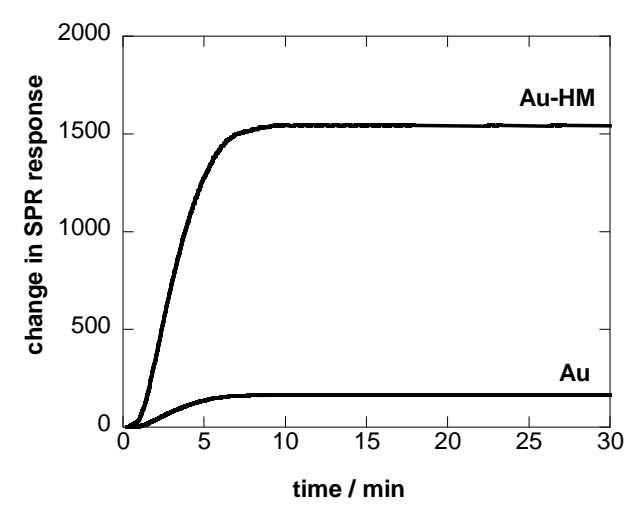

(a)

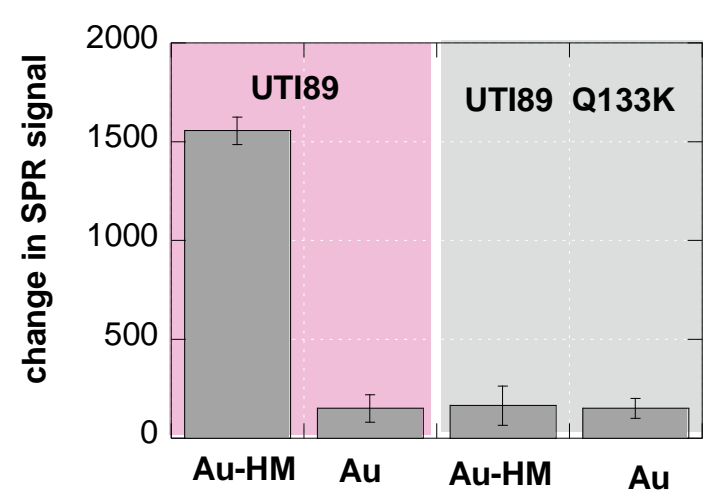

(b)

Figure 2. (a) SPR sensogram of affinity interaction of $E$. coli UTI $\left(10^{8} \mathrm{cfu} / \mathrm{mL}\right)$ with Au and $\mathrm{Au}-\mathrm{HM}$ interfaces; flow rate $=20 \mu \mathrm{L} / \mathrm{min}$; (b) bar graph diagrams of the change in SPR signals of $\mathrm{Au}$ and $\mathrm{Au}-\mathrm{HM}$ interfaces upon interaction for $30 \mathrm{~min}$ at a flow rate $=20 \mu \mathrm{L} / \mathrm{min}$ with UTI 89 and UTI89 Q133K.

The experiments carried out so far were performed at a flow rate of $20 \mu \mathrm{L} \cdot \mathrm{min}^{-1}$ in line with other SPR experiments [35]. Fluid flow is, however, an important factor in microbial deposition [36,37] and can be controlled in the flow chamber of the SPR cell by changing the flow rate. An increase in flow rate is expected to stimulate attachment of pathogens due to an increase in microbial transport towards the substrate. In other words, an increase in flow rate results in faster adhesion kinetics, where the SPR signal is saturating more rapidly. The increased shear force might, in addition, lead to a larger amount of bacteria adhering to the SPR interface, observable as an increased height of the plateau in the 
sensogram. There is, however, a critical flow rate beyond which detachment rather than adhesion of bacteria will occur. This critical flow rate varies from strain to strain and depends in addition on the involved surface. In the case of $E$. coli, the shear-force properties of FimH have been demonstrated previously using yeast mannan, mannose linked to bovine-serum-albumin, or guinea pig red blood cells, all of which are receptors for type 1 fimbriae [22,24,38,39].

We therefore investigated the influence of flow rate on the binding strength of $E$. coli UTI89 onto $\mathrm{Au}$ and $\mathrm{Au}-\mathrm{HM}$. The microfluidic channel used in combination with the SPR setup allowed us to vary the flow rate between 5 and $100 \mu \mathrm{L} \cdot \mathrm{min}^{-1}$, which corresponds to a shear of $\approx 5-100 \mathrm{mPa}$ $\left(0.005-0.1 \mathrm{pN} / \mu \mathrm{m}^{2}\right)$, a range used by others [22,40]. Figure 3a shows the binding of E. coli UTI89 at different flow rates to $\mathrm{Au}$ and $\mathrm{Au}-\mathrm{HM}$. In the case of unmodified gold SPR interfaces, the flow rate has no effect on the change in the SPR signal and thus the adhesion strength of E. coli UTI89. In fact, almost no adhesion is observed for gold only. This was in contrast to the Au-HM interface, where E. coli adhesion increased strongly with increasing flow rate from $5-30 \mu \mathrm{L} \cdot \mathrm{min}^{-1}$, where a maximum in SPR response was reached. Higher flow rates resulted in a gradual decrease in the SPR signal. At $90 \mu \mathrm{L} \cdot \mathrm{min}^{-1}$, about half of the maximal value was reached, and completely dropped to very low values at $100 \mu \mathrm{L} \cdot \mathrm{min}^{-1}$. Interestingly, the increase in adhesion until a flow of $30 \mu \mathrm{L} \cdot \mathrm{min}^{-1}$ is more rapid than the decrease in adhesion above the maximum value. The results presented in Figure 3a clearly indicate the mannose-specific mechanism of the flow-rate-dependent E. coli adhesion to Au-HM. From Figure $3 \mathrm{~b}$, the time to reach a maximal adhesion is $\approx 5-8 \mathrm{~min}$ and depends on the flow rate. While the protein FimH is highly conserved in E. coli UTI89, mutations in the binding pocket could, however, influence adhesion under shear flow. We were thus intrigued to investigate the binding characteristics of strain UTI89 Q133K and of UTI89 $\Delta$ fimH. In the case of bacterial strain UTI89 $\Delta$ fimH, the capacity to bind to bladder cells is lost due to the incapacity to form normal type-1 pili in the absence of the FimH protein [41]. As seen in Figure 3c, no shear-force enhanced adhesion could be observed for this strain: while there is a small increase in the SPR signal at a flow rate of $30 \mu \mathrm{L} \cdot \mathrm{min}^{-1}$ in the case of UTI89 Q133K, the SPR signal upon the addition of UTI89 $\Delta$ fimH is completely constant for the different flow rates measured. This is line with reports that fimbrial proteins and in particular the FimH adhesin play a key role in the adherence of uropathogenic E. coli to urothelial surfaces. A loss of fimbriae results in the impossibility of adhering to mannose-carrying surfaces and ultimately to the formation of biofilms.

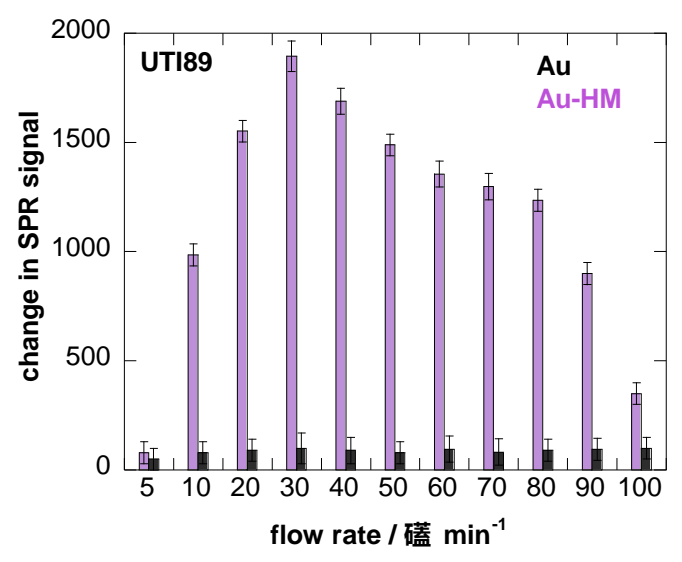

(a)

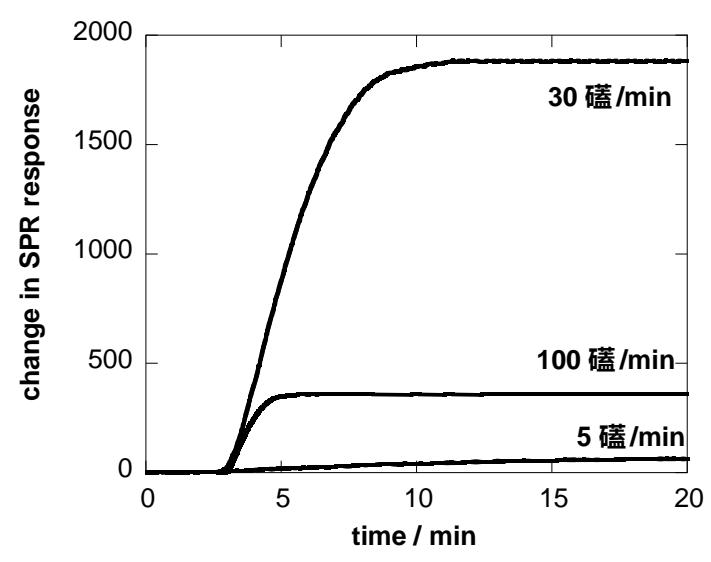

(b)

Figure 3. Cont. 


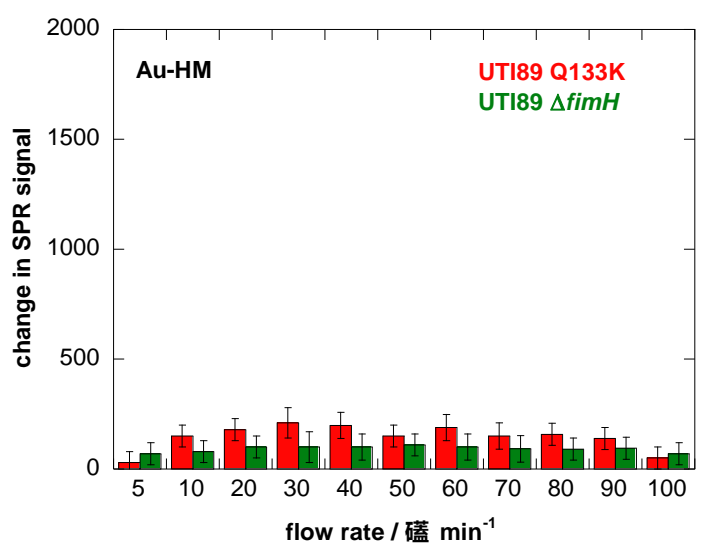

(c)

Figure 3. Binding affinity of E. coli UTI89 $\left(10^{8} \mathrm{cfu} / \mathrm{mL}\right)$ to $\mathrm{Au}$ and $\mathrm{Au}-\mathrm{HM}$ as a function of flow rate. (a) Bar graph of change in SPR signal upon addition of E. coli UTI $\left(10^{8} \mathrm{cfu} / \mathrm{mL}\right)$; (b) SPR sensogram for three different flow rates; (c) binding affinity of E. coli UTI89 Q133K $\left(10^{8} \mathrm{cfu} / \mathrm{mL}\right)$ and UTI89 $\Delta$ fimH $\left(10^{8} \mathrm{cfu} / \mathrm{ml}\right)$ to Au-HM surfaces as a function of flow rate.

\section{Conclusions}

In conclusion, the use of microchannels in SPR instrumentation has been shown to be adequate to investigate the shear-force- and surface-ligand-based microbial attachment capacities of $E$. coli UTI89 strains. Changing the flow rate between 5 and $100 \mu \mathrm{L} \cdot \mathrm{min}^{-1}$ (shears of $5-100 \mathrm{mPa}$ ) shows that the strongest affinity of $E$. coli UTI89 to aminoheptyl $\alpha$-D-mannopyranoside modified surfaces occurs at $30 \mu \mathrm{L} \cdot \mathrm{min}^{-1}$. The results presented in this work clearly point towards the influence of flow rate on the binding capability of pathogens. This study also indicates that flow-rate-induced adhesion requires specific ligand-receptor interaction, as between surface-anchored mannose units and FimH present at the distal end of E. coli UTI89. Mutation at this very end, as for E. coli UTI89 Q133K, results in a predominant loss of adhesion and the hampering of type-1 fimbrial biogenesis, through fim $H$ gene deletion, which completely abolishes shear-force-based adhesion. It is hoped that this work will widen the possibilities of studying bacterial colonization with the ultimate goal of adding to the understanding of the complex ways in which bacteria adhere to surfaces.

\section{Acknowledgments}

Rabah Boukherroub and Sabine Szunerits gratefully acknowledge financial support from the Centre National de Recherche Scientifique (CNRS), the University Lille 1 and Nord Pas de Calais region. Sabine Szunerits thanks the Institut Universitaire de France (IUF) for financial support. Florin Oancea and Stefan-Ovidiu Dima acknowledge financial support from the France-Roumanie Brâncuşi projects 707 and PN2-PCCA-0846 CERES contract no. 159/2014. Stefan-Ovidiu Dima gratefully acknowledges the financial support from the Sectoral Operational Programme Human Resources Development 2007-2013 of the Ministry of European Funds through the Financial Agreement POSDRU/159/1.5/S/134398. Oleksandr Zagorodko thanks Sensia for a research scholarship. 
Julie Bouckaert and Sebastien Gouin have been financed by the French Agence Nationale de la Recherche (ANR-12-BSV5-0016-01).

\section{Author Contributions}

Sabine Szunerits, Rabah Boukherroub, Oleksandr Zagorodko, Stefan-Ovidiu Dima, Florin Oancea, Iban Larroulet, Aritz Yanguas Serrano designed and performed SPR measurements. Julie Bouckaert, Tetiana Dumych, and Rostyslav Bilyy selected, cultivated and quantified the bacterial clones. Dimitri Alvarez Dorta and Sebastien G. Gouin synthesized carbohydrate compounds. Sabine Szunerits and Julie Bouckaert interpreted the data and wrote the manuscript.

\section{Conflicts of Interests}

The authors declare no conflict of interest

\section{References}

1. Scarano, S.; Mascini, M.; Turner, A.P.F.; Minunni, M. Surface plasmon resonance imaging for affinity-based biosensors. Biosens. Bioelectron. 2010, 25, 957-966.

2. Cooper, M.A. Lable-free screening of bio-molecular interactions. Anal. Bioanal. Chem. 2003, 377, 834-842.

3. Subramanian, P.; Lesniewski, A.; Kaminska, I.; Vlandas, A.; Vasilescu, A.; Niedziolka-Jonsson, J.; Pichonat, E.; Happy, H.; Boukherroub, R.; Szunerits, S. Lysozyme detection on aptamer functionalized graphene-coated SPR interfaces. Biosens. Bioelectron. 2013, 50, 239-243.

4. Zagorodko, O.; Spadavecchia, J.; Serrano, Y.S.; Larroulet, I.; Pesquera, A.; Zurutuza, A.; Boukherroub, R.; Szunerits, S. Highly sensitive detection of DNA hybridization on commercialized graphene coated surface plasmon resonance interfaces. Anal. Chem. 2014, 86, 11211-11216.

5. Homola, J. Surface plasmon resonance sensors for detection of chemical and biological species. Chem. Rev. 2008, 108, 462-493.

6. Homola, J.; Dostalek, J.; Chen, S.F.; Rasooly, A.; Jiang, S.Y.; Yee, S.S. Spectral surface plasmon resonance biosensor for detection of staphylococcal enterotoxin B in milk. Int. J. Food Microbiol. 2002, 75, 61-69.

7. Naimushin, A.N.; Soelberg, S.D.; Nguyen, D.K.; Dunlap, L.; Bartholomew, D.; Elkind, J.; Melendez, J.; Furlong, C.E. Detection of Staphylococcus aureus enterotoxin B at femtomolar levels with a miniature integrated two-channel surface plasmon resonance (SPR) sensor. Biosens. Bioelectron. 2002, 17, 573-584.

8. MacKenzie, C.R.; Hirama, T.; Lee, K.K.; Altman, E.; Young, N.M. Quantitative analysis of bacterial toxin affinity and specificity for glycolipid receptors by surface plasmon resonance. J. Biol. Chem. 1997, 272, 5533-5538.

9. Yu, Q.M.; Chen, S.F.; Taylor, A.D.; Homola, J.; Hock, B.; Jiang, S.Y. Detection of low-molecular-weight domoic acid using surface plasmon resonance sensor. Sens. Actuators B 2005, 107, 193-201. 
10. Kanda, V.; Kitov, P.; Bundle, D.R.; McDermott, M.T. Surface plasmon resonance imaging measurements of the inhibition of Shiga-like toxin by synthetic multivalent inhibitors. Anal. Chem. 2005, 77, 7497-7504.

11. Fratamico, P.M.; Strobaugh, T.P.; Medina, M.B.; Gehring, A.G. Detetion of Escherichia coli O157:H7 using a surface plasmon resonance biosensor. Biotechnol. Tech. 1998, 12, 571-576.

12. Taylor, A.D.; Ladd, J.; Yu, Q.; Chen, S.; Homola, J.; Jiang, S. Quantitative and simultaneous detection of four foodborne bacterial pathogens with a multi-channel SPR sensor. Biosens. Bioelectron. 2006, 22, 752-758.

13. Arya, S.K.; Singh, A.; Naidoo, R.; Wu, P.; McDermott, M.T.; Evoy, S. Chemically immobilized T4-bacteriophage for specific Escherichia coli detection using surface plasmon resonance. Analyst 2011, 136, 486-492.

14. Oh, B.K.; Lee, W.Y.; Chun, B.S.; Bae, Y.M.; Lee, Y.M.; Choi, J.W. The fabricaiton of protein chip based on surface plasmon resonance for detections of pathogens. Biosens. Bioelectron. 2005, 20, 1847-1850.

15. Maalouf, R.; Fournier-Wirth, C.; Coste, J.; Chebib, H.; Saikali, Y.; Vittori, O.; Errachid, A.; Cloarec, J.P.; Martelet, C.; Jaffrezic-Renault, N. Label-free detection of bacteria by electrochemical impedance spectroscopy: Comparision to surface plasmon resonance. Anal. Chem. 2007, 79, 4879-7886.

16. Yazagan, I.; Noah, N.M.; Toure, O.; Zhang, S.; Sadik, O.A. Biosensor for selective detection of E. coli in spinach using the strong affinity of derivatized mannose with fimbrial lectin. Biosens. Bioelectron. 2014, 61, 266-273.

17. Subramanian, P.; Barka-Bouaifel, F.; Bouckaert, J.; Yamakawa, N.; Boukerroub, R.; Szunerits, S. Graphene-coated surface plasmon resonance interfaces for studying the interactions between bacteria and surfaces. ACS Appl. Mater. Interfaces 2014, 6, 5422-5431.

18. Durka, M.; Buffet, K.; Iehl, J.; Holler, M.; Nierengarten, J.F.; Taganna, J.; Bouckaer, T. J.; Vincent, S.P. The functional valency of dodecamannosylated fullerenes with Escherichia coli FimH-Towards novel bacterial antiadhesives. Chem. Commun. 2011, 47, 1321-1323.

19. Le, T.I.; Aprikian, P.; Kidd, B.A.; Forero-Shelton, M.; Tchesnokova, V.; Rajagopal, P.; Rodriguez, V.; Interlandi, G.; Klevit, R.; Vogel, V.; et al. Structural basis for mechanical force regulation of the adhesin FimH via finger trap-like beta sheet twisting. Cell 2010, 141, 645-655.

20. Pereverzev, Y.V.; Preshdo, O.V.; Forero, M.; Sokurenko, E.V.; Thomas, W.E. The two-pathway model for the catch-slip transition in biological adhesion. Biophys. J. 2005, 89, 1446-1454.

21. Sharma, P.K.; Gibcus, M.J.; van der Mei, H.C.; Busscher, H.J. Influence of fluid shear and microbubbles on bacterial detachment from a surface. Appl. Environ. Microbiol. 2005, 71, 3668-3673.

22. Thomas, W.; Forero, M.; Yakovenko, O.; Nilsson, L.; Vicini, P.; Sokurenko, E.; Vogel, V. Catch-bond model derived from allostery explains force-activated bacterial adhesion. Biophys. J. 2006, 90, 753-764.

23. Sokurenko, E.V.; Vogel, V.; Thomas, W.E. Catch bond mechanism of force-enhanced adhesion: Counter-intuitive, elusive but widespread? Cell Host Microbe 2008, 16, 314-323. 
24. Yakovenko, O.; Sharma, S.; Forero, M.; Tchesnokova, V.; Aprikian, P.; Kidd, B.; March, A.; Vogel, V.; Sokurenko, E.; Thomas, W. FimH forms catch bonds that are enhanced by mechanical force due to allosteric regulation. J. Biol. Chem. 2008, 283, 11596-11605.

25. Klinth, J.E.; Castelain, M.; Uhlin, B.E.; Axner, O. The influence of $\mathrm{pH}$ on the specific adhesion of P piliated Escherichia coli. PLoS ONE 2012, 7, 1-8.

26. Bouckaert, J.; Berglund, J.; Schembri, M.; de Genst, E.; Cools, L.; Wuhrer, M.; Hung, C.S.; Pinker, J.; Slattegard, R.; Zavialov, A.; et al. Receptor binding studies disclose a novel class of high-affinity inhibitors of the Escherichia coli FimH adhesin. Mol. Microbiol. 2005, 55, 441-455.

27. Londardi, E.; Moonens, K.; Buts, L.; de Boer, A.R.; Olsson, J.D.M.; Weiss, M.S.; Fabre, E.; Guérardel, Y.; Deelder, A.M.; Oscarson, S.; et al. Structural sampling of glycan interaction profiles reveals mucosal receptors for fimbrial adhesins of enterotoxigenic Escherichia coli. Biology 2013, 2, 894-917.

28. Chen, S.L.; Hung, C.S.; Pinkner, J.S.; Walker, J.N.; Cusumano, C.K.; Li, Z.; Bouckaert, J.; Gordone, J.I.; Hultgren, S.J. Positive selection identifies an in vivo role for FimH during urinary tract infection in addition to mannose binding. Proc. Natl. Acad. Sci. USA 2009, 106, 22439-22444.

29. Yan, X.; Delgado, M.; Fu, A.; Alcouffe, P.; Gouin, S.G.; Fleury, E.; Katz, J.L.; Ganachaud, F.; Bernard, J. Simple but precise engineering of functional nanocapsules through nanoprecipitation. Angew. Chem. Int. Ed. 2014, 53, 6910-6913.

30. Barras, A.; Martin, F.A.; Bande, O.; Baumann, J.S.; Ghigo, J.M.; Boukherroub, R.; Beloin, C.; Siriwardena, A.; Szunerits, S. Glycan-functionalized diamond nanoparticles as potent E. coli anti-adhesives. Nanoscale 2013, 5, 2307-2316.

31. Jones, C.; Pinker, J.S.; Roth, R.; Heuser, J.; Nicholes, A.V.; Abraha, S.N.; Hultgren, S.J. FimH adhesin of type 1 pili is assembled into a fibrillar tip structure in the Enterobacteriaceae. Proc. Natl. Acad. Sci. USA 1995, 92, 2081-2085.

32. Touaibia, M.; Wellens, A.; Shiao, T.C.; Wang, Q.; Sirois, S.; Bouckaert, J.; Roy, R. Mannosylated G(0) dendrimers with nanomolar affinities to Escherichia coli FimH. ChemMedChem 2007, 2, 1190-1201.

33. Maalouli, N.; Barras, A; Siriwardena, A.; Boukherroub, R.; Szunerits, S. Comparison of photo- and $\mathrm{Cu}(\mathrm{I})$-catalyzed "click" chemistries for the formation of carbohydrate SPR interfaces. Analyst 2013, 138, 805-812.

34. Alves, I.; Kurylo, I.; Coffinier, Y.; Siriwardena, A.; Zaitsev, V.; Harté, E.; Boukherroub, R.; Szunerits, S. Plasmon waveguide resonances for the sensing of glycans-lectin interactions. Anal. Chim. Acta 2015, 873, 71-79.

35. Bouckaert, J.; Mackenzie, J.; de Paz, J.L.; Chipwaza, B.; Choudhury, D.; Zavialov, A.; Mannerstedt, K.; Anderson, J.; Pierard, D.; Wyns, L.; et al. The affinity of the FimH fimbrial adhesin is receptor-driven and quasi-independent of Escherichia coli pathotypes. Mol. Microbiol. 2006, 61, 1556-1568.

36. Bakker, D.P.; BusScher, H.J.; van der Mei, H.C. Bacterial deposition in a parallel plate and a stagnation point flow chamber: Microbial adhesion mechanisms depend on the mass transport conditions. Microbiology 2002, 148, 597-603.

37. Boks, N.P.; Norde, W.; van der Mei, H.C.; Busscher, H.J. Forces involved in bacterial adhesion to hydrophilic and hydrophobic surfaces. Microbiology 2008, 154, 3122-3133. 
38. Tchesnokova, V.; Aprikian, P.; Yakovenko, O.; Larock, C.; Kidd, B.A.; Vogel, V.; Thomas, W.; Sokurenko, E. Integrin-like allosteric properties of the catch bond-forming FimH adhesin of Escherichia coli. J. Biol. Chem. 2008, 283, 7823-7833.

39. Thomas, W.; Trintchina, E.; Forero, M.; Vogel, V.; Sokurenko, E.V. Bacterial adhesion to target cells enhanced by shear force. Cell 2002, 109, 913-923.

40. Lecuyer, S.; Rusconi, R.; Shen, Y.; Forsyth, A.; Vlamakis, H.; Kolter, R.; Stone, H.A. Shear Stress Increases the Residence Time of Adhesion of Pseudomonas aeruginosa. Biophys. J. 2011, 100, 341-350.

41. Wright, K.J.; Seed, P.C.; Hultgren, S.J. Development of intracellular bacterial communities of uropathogenic Escherichia coli depends on type 1 pili. Cell. Microbiol. 2007, 9, 2230-2241.

(C) 2015 by the authors; licensee MDPI, Basel, Switzerland. This article is an open access article distributed under the terms and conditions of the Creative Commons Attribution license (http://creativecommons.org/licenses/by/4.0/). 